\title{
Antimicrobial Application and Assessment of Green Synthesized Silver Nanoparticles Using Aqueous Leaf Extract of Ficus Copiosa
}

\author{
David Timi ${ }^{1}$, Subramaniyam Gopalakrishnan ${ }^{1}$ and Macquin Maino ${ }^{2}$ \\ ${ }^{1}$ Department of Applied Sciences, PNG University of Technology, PMB, Lae, Papua New Guinea. \\ ${ }^{2}$ Department of Agriculture, PNG University of Technology, PMB, Lae, PNG. \\ david.timi@pnguot.ac.pg, subramaniyam.gopalakrishnan@pnguot.ac.pg; macquin.maino@pnguot.ac.pg
}

\begin{abstract}
Plant mediated green-synthesized silver nanoparticles (AgNPs) and the bioactivity on pathogenic microorganisms is discussed. In the present investigation, aqueous leaf extracts of a medicinal plant, Ficus copiosa was utilized to construct AgNPs. The synthesized AgNPs was characterized by Ultraviolet-visible (UV-vis), Fourier Transform-infrared (FT-IR), X-ray Diffraction (XRD) spectrometer and Scanning Electron Microscopy (SEM) analysis. The phytosynthesized AgNPs exhibited comparable antimicrobial activity with two reference antibiotics against five indicator micro-organisms including two gram-positive (G+) bacteria, two gram-negative (G-) bacteria and a Protozoa (Pz). Study of the minimum inhibition concentration shows the two gram-negative bacteria to be more susceptible to AgNPs than the two grampositive bacteria. The organisms included in the study are namely, B. Subtilis (G+), S. aureus (G+), E. coli (G-), S. pneumonia (G-) and T. vaginalis (Pz). Agar Disc diffusion technique was employed to assess the efficacy of the silver nanoparticles on the micro-organisms.
\end{abstract}

Keywords: Silver nanoparticles, Antimicrobial Application, Green Synthesis, Ficus copiosa

\section{Background}

Nanotechnology is a rapidly growing area of research involving very tiny microscopic materials at nanoscale level (1-100 nm). ${ }^{1}$ It has application in all areas of science including chemistry, physics, biology, medicine and engineering disciplines because of the unique physical, chemical and biological properties displayed by certain materials at nanoscale. ${ }^{1,2}$ Silver nanoparticle (AgNPs) is one such nanomaterial that has drawn attention for its application in biological sciences due to its outstanding chemical and biological properties. ${ }^{3}$ Silver nanoparticle is biocompatible as compared to other metal nanoparticles and has excellent antimicrobial property due to its high surface to volume ratio. Thus, it is incorporated into various consumer products and has wide application in nanomedicine. ${ }^{3,4}$

Physical, chemical and biological methods are followed in the construction of nanoparticles including AgNPs. ${ }^{5}$ With the biological method, biomolecules obtained from bacteria, fungi and plants are utilized to construct AgNPs. ${ }^{6}$ While physical method involves the top-down approach, both the chemical and biological methods take the bottom-up approach. ${ }^{5,6}$ From all these methods, biological or green synthesis 
David Timi, Subramaniyam Gopalakrishnan and Macquin Maino; Antimicrobial Application and Assessment of Green Synthesized Silver Nanoparticles Using Aqueous Leaf Extract of Ficus Copiosa. Journal of Biomedical Engineering and Medical Imaging, Volume 6, No 3, June (2019), pp 6-15

is more eco-friendly as it involves the use of benign biomolecules unlike physical and chemical methods. Among the green methods of synthesis, phytosynthesis is inexpensive and the more convenient method. ${ }^{6}$ Thus, plant mediated green synthesis of nanoparticles has gained more attention lately due to the convenience and its eco-friendly approach. Since the pioneering work by Gardea-Toresday et al. (1999) on phytosynthesis of gold nanoparticles, there have been many literary reports on the plant mediated green synthesis of silver nanoparticles synthesized and tested on different biological applications. ${ }^{7}$ Examples of some of these plants include Psidium guajava, ${ }^{8}$ Euphorbia hirta, ${ }^{9}$ Nerium indicum, ${ }^{9}$ Trianthema decandra, ${ }^{10}$ Achyranthes aspera, ${ }^{11}$ Ocimum sanctum, ${ }^{12}$ Andrographis paniculata, ${ }^{13}$ Allium cepa, ${ }^{14}$ Cucumis sativus, ${ }^{15}$ Asiatic pennywort, ${ }^{15}$ Bryophilum $s p,{ }^{16}$ Emblica officinalis, ${ }^{17}$ Pterocarpus santalinus, ${ }^{18}$ Wedelia urticifolia, ${ }^{19}$ Catharanthus roseus, ${ }^{20}$ Carica papaya, ${ }^{6}$ Eclipta prostrate ${ }^{6}$ and Zingiber officinale. ${ }^{15}$

In this study, aqueous leaf extracts of a medicinal plant, Ficus copiosa (Moraceae), was utilized to construct silver nanoparticles and the antimicrobial potency of these nanoparticles were tested against five indicator pathogenic micro-organisms. F. copiosa (Figure 1.1) is a small to medium size tree that grows up to 5-20 meters tall. It is found in both coastal and inland regions in both primary and secondary forest at elevations up to 1700 meters altitude. ${ }^{21}$

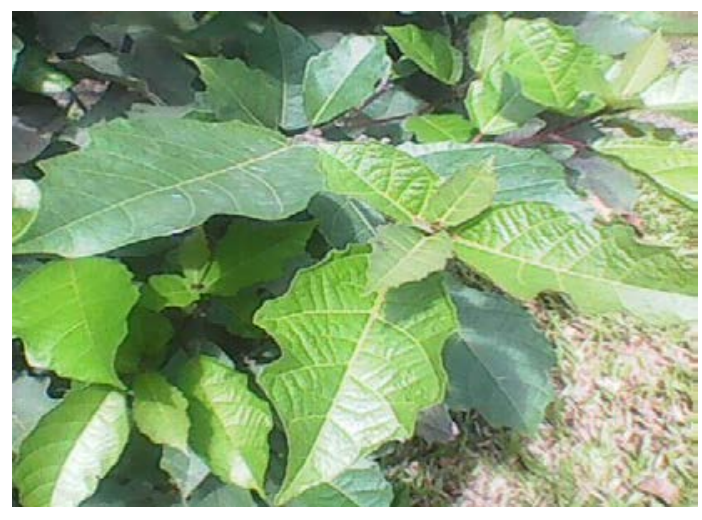

Figure 1: Ficus copiosa

This plant species have different ethno-botanical uses in Papua New Guinea. The soft wood is used mainly as a source of fuel while the inner bark is used to weave strings for string bags. Young leaves and shoots are cooked and eaten as leafy vegetable and additionally, both young and ripe fruits are often eaten raw. ${ }^{21}$ The plant further has several ethno-medicinal applications among different ethnic tribes. In the island of Bougainville, the people of Buin use the plant to treat arthritis and malaria while in Siwai the plant is used to treat boil. Additionally, in East New Britain, fresh fruit latex of this fig species is applied onto boils and its leaves are crushed and rubbed on to stomach to alleviate stomach-ache. ${ }^{21,22}$ In the Trobriand Islands, fresh leaves are used as a poison antidote while the roots and leaves are used to treat stomach-ache. ${ }^{23}$ There has been no specific chemical reference made of this species, but other related species of the genus are reported to contain alkaloids, flavanoids, terpenoids, steroids, coumarins, carboxylic acids and glycosides. ${ }^{24}$ 


\section{Experimental}

\subsection{AgNPs synthesis - Method Validation}

Four different phytosynthetic approaches for the synthesis of silver nanoparticles were followed for method validation. These were (a) synthesis under ultra-violet light; (b) synthesis at room temperature; (c) synthesis under heat and (d) synthesis under direct sunlight. Synthesis of silver nanoparticles under direct sunlight in a clear sunny day (d) proved to be the best approach over the others as production of silver nanoparticles were faster (within minutes) and the yield was much higher. Therefore, this approach was taken for the synthesis of silver nanoparticles. The molar concentration of silver nitrate solution used was 0.003 moles $\mathrm{L}^{-1}$ (3.0 milli-moles).

\subsection{Preparation of Silver Nanoparticles (AgNPs)}

\subsubsection{Preparation of Silver Nitrate Solution}

From an analytical balance, $9.5 \mathrm{~g}$ of silver nitrate was weighed and transferred into a $500 \mathrm{ml}$ volumetric flask, dissolved and made up to volume with distilled water to a concentration of 0.1177 moles $\mathrm{L}^{-1}$. From this $2.5 \mathrm{ml}$ were transferred to $100 \mathrm{ml}$ volumetric flask with a $5 \mathrm{ml}$ pipette and diluted to mark with distilled water, giving a final concentration of 0.003 moles $L^{-1}$.

\subsubsection{Sampling and Preparation of Leaf Sample}

Young matured diseases free leaves of Ficus copiosa were collected and $10 \mathrm{~g}$ of these were weighed and washed thoroughly with tap water and then rinsed with distilled water.

\subsubsection{Aqueous Extract of Leaf Sample}

$10 \mathrm{~g}$ of the leaves were chopped up to smaller pieces with a kitchen knife and placed into $250 \mathrm{ml}$ volumetric flask. $200 \mathrm{ml}$ of distilled water were added and heated on a bunsen burner to the first sign of boiling, then removed and left to cool to room temperature. These were then filtered with a Whatman No. 1 filter paper and the filtrates were used for the synthesis of silver nanoparticles.

\subsubsection{Synthesis of Silver Nanoparticles}

With a measuring cylinder, $50 \mathrm{ml}$ of aqueous plant extracts were measured and transferred into $250 \mathrm{ml}$ volumetric flasks and to these $100 \mathrm{ml}$ of 3.0 milli-moles of silver nitrate were added, gently shaken and placed under direct sunlight. Colour changed from yellow to dark brown of the mixture indicated the formation of silver nanoparticles followed by agglomeration of the particles. After about two hours, this was removed and placed in a room for agglomerated colloidal AgNPs to settle over-night before they were centrifuged at $2500 \mathrm{rpm}$. The supernatants were discarded and the silver nanoparticles were washed with about $50 \mathrm{ml}$ of distilled water and centrifuged again. The same washing process was repeated three times and the AgNPs for bioassay were stored as aqueous suspension $(30 \mathrm{ml}$ ) in a vial. Those for characterization were stored as dried samples ( $250 \mathrm{mg}$ ) and sent away for spectral analysis.

\subsubsection{Characterization}

Four spectroscopic techniques were employed to characterize the biosynthesized AgNPs. They included UV-Visible spectroscopy, Fourier Transform Infra-red spectroscopy (FT-IR), X-ray Diffraction spectroscopy (XRD) and Scanning Electron Microscopy (SEM). 
David Timi, Subramaniyam Gopalakrishnan and Macquin Maino; Antimicrobial Application and Assessment of Green Synthesized Silver Nanoparticles Using Aqueous Leaf Extract of Ficus Copiosa. Journal of Biomedical Engineering and Medical Imaging, Volume 6, No 3, June (2019), pp 6-15

The Uv-vis. analysis of the phytosynthesized AgNPs was carried out using a Varian Cary 50 Bio Uv-visible spectrophotometer. The absorption maxima $\left(\lambda_{\max }\right)$ of the coloured solution of AgNPs in a cuvette $(1 \mathrm{~cm}$ path length) were taken from a wavelength range set at $200-700 \mathrm{~nm}$ and slit width at $1 \mathrm{~nm}$. FT-IR analysis was carried out in the range of 450 to $4,000 \mathrm{~cm}^{-1}$. XRD pattern was recorded using $\mathrm{Cu} K \alpha$ radiation $(\lambda=$ $1.54060 \AA$ ) with nickel monochromator in the range of $2 \theta$ from $10^{\circ}$ to $70^{\circ}$. The morphology and size range of the synthesized AgNPs was examined by SEM.

\subsection{Bioassay}

\subsubsection{Preparation of Test Micro-organisms}

With a pre-flamed inoculating loop, 5 test microbials (4 bacteria and a protozoa) were obtained from the mother cultures, transferred to sterilized nutrient broth (oxoid) in McCartney bottles and all five organisms were subcultured overnight at $37^{\circ} \mathrm{C}$. Nutrient broth (13 grams) was dissolved in a litre of distilled water and sterilized in an autoclave at $121^{\circ} \mathrm{C}$ for 15 minutes.

\subsubsection{Preparation of Assay plates and Paper Discs}

28 grams of nutrient agar (oxoid) were dissolved in 1 litre of distilled water and sterilized in an autoclave for 15 minutes at $121^{\circ} \mathrm{C}$. After sterilization, 15 to $20 \mathrm{ml}$ of nutrient agar were dispensed into sterile plastic petri-discs having internal diameter of $9 \mathrm{~cm}$. After the agar solidified, the plates were stored in a refrigerator at $4^{\circ} \mathrm{C}$ awaiting bioassay.

Paper discs $(6 \mathrm{~mm})$ were cut out from Whatman millipore filter paper ( $1 \mathrm{~mm}$ thick) with a paper holepuncher and were sterilized at temperature of $120^{\circ} \mathrm{C}$ in an oven for about 24 hours.

\subsubsection{In-vitro Anti-microbial Test}

To the nutrient agar plates, $100 \mu \mathrm{L}$ of subcultured micro-organisms were transferred with a sterile micropipette and streaked evenly with a glass hocky rod under sterile condition. To the seeded media, paper discs impregnated with $30 \mu \mathrm{L}$ suspension of AgNPs were gently pressed down to ensure complete contact and were incubated at $37^{\circ} \mathrm{C}$ for $18-24$ hours. After incubation, zones of inhibitions were measured $(\mathrm{mm})$ and tabulated (Table 1 ).

\subsubsection{Determination of Minimum Inhibition Concentration (MIC).}

To observe MIC of the AgNPs, the five organisms were tested using the same disc diffusion technique. The organisms tested include Bacillus subtilis, Staphylococcus aureus, Escharichia coli, Streptococcus pneumonia and Trichomonas vaginalis.

From the aqueous suspension of AgNPs, $2.0 \mu \mathrm{L}$ were removed with a micropipette and transferred to glass vials. These were then diluted by adding appropriate volume of distilled water using a $1000 \mu \mathrm{L}$ micropipette. Several dilutions were prepared, ranging from $5 x$ to $100 x$ dilution. Applying the bioassay method described in Section 2.2.3 above, the dilution that exhibited minimal growth around the edge of the $6 \mathrm{~mm}$ paper disc was taken as the minimum inhibition concentration. 


\section{Results and Discussions.}

\subsection{Colour Change}

The formation of silver nanoparticles was evident from the change of colour of the reaction mixture from a yellow to a dark brown solution within twenty minutes (Figure 2).

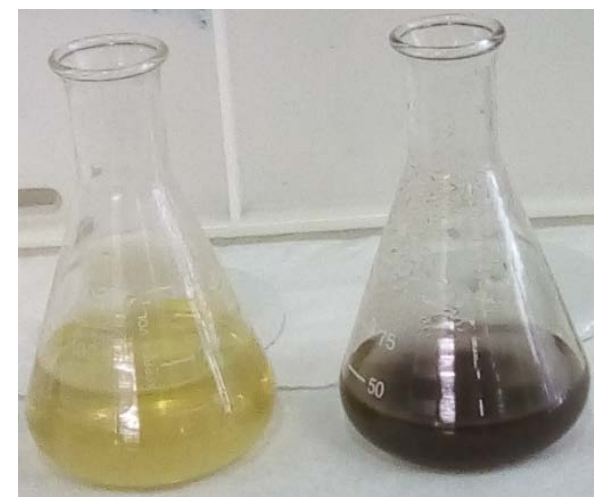

Figure 2: Formation of AgNPs indicated by the change of colour from yellow to a brown solution.

\subsection{Characterization}

The ultraviolet-visible (UV-vis) spectral analysis exhibited an observable peak ( $\lambda$ max) at $440 \mathrm{~nm}$ which corresponds to the Uv-vis absorption wavelength of the surface plasmon resonance of AgNPs (Figure 3). Various reports have established that the resonance peak of silver nanoparticles appears around this region (400-500 nm).25 The FT-IR analysis demonstrated stretching and bending frequency signals of the reducing and capping biological molecule at 3366 (-NH2), $3220(-\mathrm{NH} 2), 2015,1617$ (C=C), 1373 (C-H bending), 1224 (C-O) and $1062 \mathrm{~cm}-1$ (Figure 4).26 The XRD pattern (Figure 5) shows two distinct $2 \theta$ peak values at around 380 and 640 and the third expected pattern at around 440 is relatively weak to stand out against the background signal possibly due to the lack of mono-suspension of the colloidal nanoparticles (Figure 6). This XRD pattern (Figure 5) corresponds to Braggs diffractions at 111(380), 200 (440) and 220 (640) planes of the lattice structure of silver (Ag).25 Scanning electron microscopy (SEM) image (Figure 6) shows the agglomerated AgNPs to be predominantly spherical in morphology with their size distribution ranging from 20 to $50 \mathrm{~nm}$.

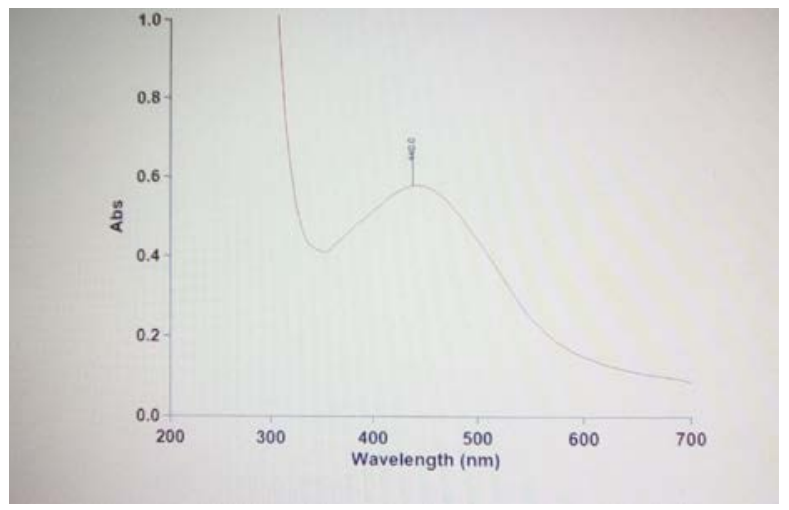

Figure 3: UV-vis. spectrum of Ag NPs constructed from F. copiosa leaf extract. 


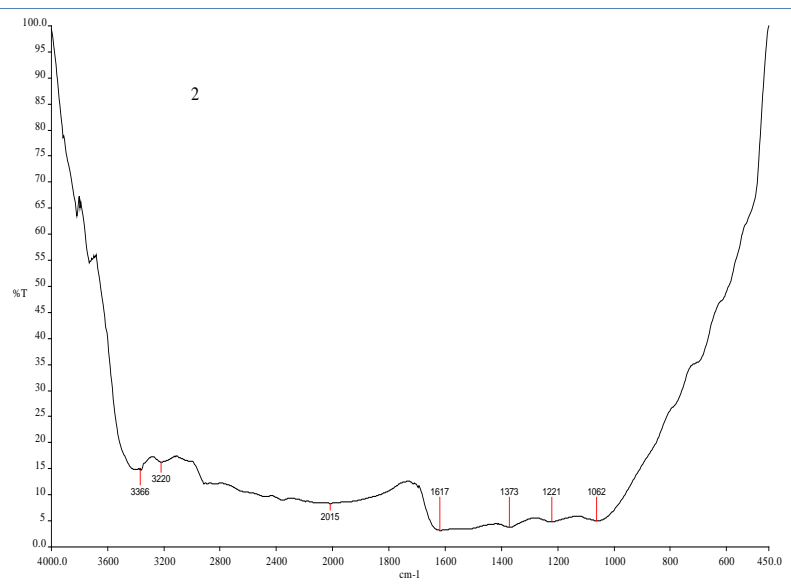

Figure 4: FT-IR spectrum of silver nanoparticles synthesized using F. copiosa leaf extract.

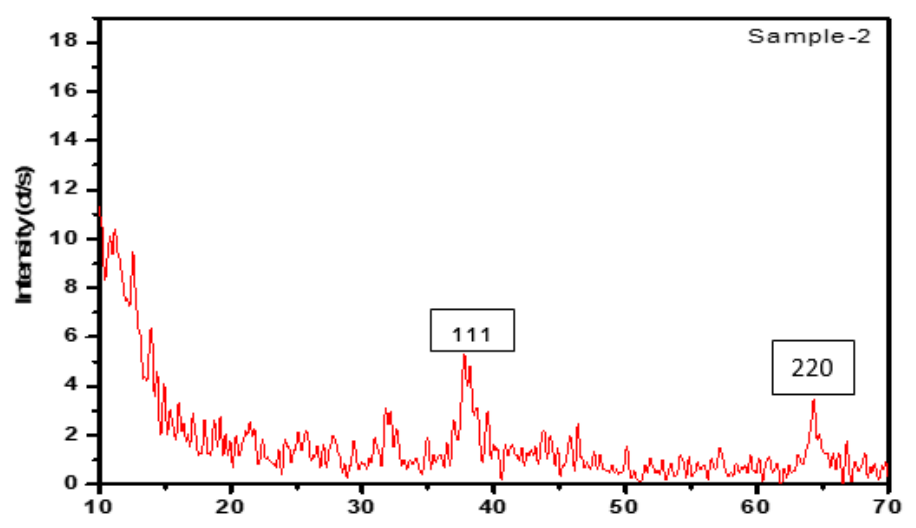

Figure 5: XRD pattern of synthesized silver nanoparticles from F. copiosa leaf extract.

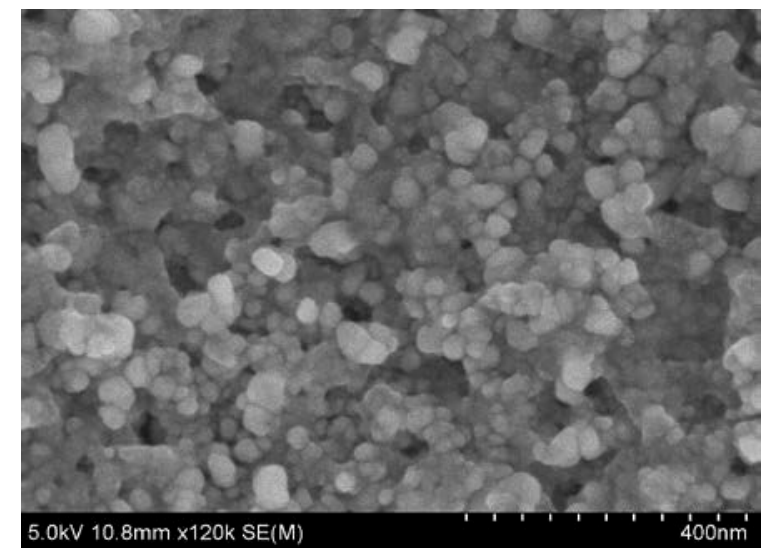

Figure 6: SEM image of Ag NPs synthesized using the leaf extract of F. copiosa.

\subsection{Bioassay}

Antimicrobial property of green synthesized AgNPs was assessed by performing bioassay against five indicator organisms including two Gram-positive bacteria (B. subtilis \& S. aureus), two Gram-negative bacteria (E. coli \& S. Pneumonia) and one Protozoa (T. vaginalis) (Table 1). The results show that all five micro-organisms were susceptible to the AgNPs synthesized using aqueous leaf extract of $F$. copiosa. The antimicrobial activity was demonstrated by the clear zones of growth inhibition of the micro-organisms 
(Figure 7). Under the experimental conditions, the synthesized AgNPs ( $30 \mu \mathrm{L}$ ) have shown to be comparable with the two reference drugs, Chloramphenicol (10 $\mu \mathrm{g})$ and Gentamycin $(10 \mu \mathrm{g})$.

Experimental results of the evaluation on the minimum inhibitory concentration (MIC) of the green synthesized silver nanoparticles are given in Table 2. MIC is the lowest concentration of an antimicrobial agent or a drug that will inhibit the visible growth of a micro-organism after overnight (18-24 hours) incubation. It is used to define the in-vitro activity of a new antimicrobial agent and often the information is used to determine MIC breakpoints. ${ }^{27}$ The two Gram-positive bacteria in this case proved to be less susceptible while both Gram-negative bacteria, and more so $T$. vaginalis were more susceptible to the potent toxic effect of AgNPs. This trend was observed by other researchers and is the result of the cell wall thickness of the two types of bacteria. ${ }^{19} \mathrm{Gram}$-positive bacteria have thicker cell walls and so are less susceptible to the toxic effects of AgNPs unlike Gram-negative bacteria that have thinner cell walls. ${ }^{19}$

There are suggestions of several hypothetical attacking sites by nanosilver leading to bacterial cell death. AgNPs can lodge in between cell walls and causes plasmolysis, leading to death of bacteria. ${ }^{28}$ If nanosilver get pass the cell wall and get into the cytoplasm, $\mathrm{Ag}^{+}$ions are released as a result of electron transfer and in doing so can interact with sulphur and phosphorus containing compounds, thus interfering with protein synthesis and DNA replications. ${ }^{19,} 28,29 \mathrm{Ag}^{+}$ions can also interact with thiol groups in enzymes such as NADH dehydrogenase and disrupt the bacterial respiratory mechanism. Another possible explanation to bacterial cell death could be linked to the formation of free radicals by AgNPs that induces oxidative stress. $^{19,29}$

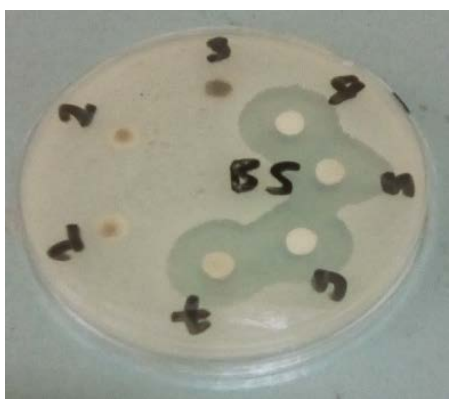

Figure 7: Clear circular zone around $6 \mathrm{~mm}$ paper disc indicating growth inhibition of bacteria induced by AgNPs.

Table 1: Antimicrobial activity of AgNPs synthesized using leaves of Ficus copiosa.

\begin{tabular}{lcccc}
\hline Name of & \multicolumn{4}{c}{ Zone of Inhibition in mm } \\
Micro-organisms & AgNPs & Gen. & Chl. & Blank \\
\hline B. Subtilis (G+) & +++ & ++ & +++ & 0 \\
S. aureus (G+) & +++ & +++ & +++ & 0 \\
E. coli $\quad(\mathrm{G}-)$ & +++ & ++ & ++ & 0 \\
S. pneumonia (G-) & ++ & ++ & + & 0 \\
T. vaginalis (Pz) & ++ & +++ & ++ & 0 \\
\hline
\end{tabular}


David Timi, Subramaniyam Gopalakrishnan and Macquin Maino; Antimicrobial Application and Assessment of Green Synthesized Silver Nanoparticles Using Aqueous Leaf Extract of Ficus Copiosa. Journal of Biomedical Engineering and Medical Imaging, Volume 6, No 3, June (2019), pp 6-15

$\mathrm{G}+=$ Gram positive bacteria; $\mathrm{G}-=$ Gram negative bacteria; $\mathrm{Pz}=$ Protozoa; Gen. = Gentamicin reference drug; Chl. = Chloramphenol reference drug; + = Inhibition zone 6-9 mm; ++ = Inhibition zone $10-19 \mathrm{~mm}$; $+++=$ inhibition zone $20-29 \mathrm{~mm} ; 0=$ No growth inhibition.

Table 2: Dilution factors (1/x) of aqueous suspension of AgNPs that produced minimum growth inhibition of 6 $\mathrm{mm}$.

\begin{tabular}{lccccc}
\hline \multirow{5}{*}{ AgNPs } & \multicolumn{5}{c}{$\begin{array}{c}\text { Dilutions } \\
(1 / \mathrm{x})\end{array}$} \\
\cline { 2 - 5 } & \multicolumn{5}{c}{ Micro-organisms } \\
\cline { 2 - 5 } B. Subtilis & S. aureus & E. coli & S. pneumonia & T. vaginalis \\
\cline { 2 - 5 } & $5 \mathrm{x}$ & $10 \mathrm{x}$ & $30 \mathrm{x}$ & $20 \mathrm{x}$ & $70 \mathrm{x}$ \\
\hline
\end{tabular}

\section{Conclusion}

In the present investigation, green synthesized AgNPs from aqueous leaf extract of a medicinal plant, $F$. copiosa was assayed to examine the microbiological activity against five indicator disease causing microorganisms. The synthesized AgNPs suspensions at $30 \mu \mathrm{L}$ have shown antimicrobial activity similar to the two reference material of gentamycin $(10 \mu \mathrm{g})$ and chloramphencol $(10 \mu \mathrm{g})$. The investigation have also indicated, $T$. vaginalis to be more susceptible to the AgNPs followed by the two gram-negative bacteria and the less susceptible organisms to be the two gram-positive bacteria. Overall, this finding supports various literature reports on the broad range antimicrobial activity of AgNPs. The study has further shown that biologically active silver nanoparticles can by constructed from the aqueous leaf extract of $F$. copiosa giving added value to the medicinal use of this plant. This bioactive AgNPs can be considered for application in some consumer products as is the case with AgNPs produced from other methods.

\section{ACKNOWLEDGEMENT}

The authors are grateful to the Research Committee of PNG University of Technology for the funding assistance. Mrs Rag Sipou and Mr. Pelis Wangiwan assisted in the microbiological bioassay.

\section{REFERENCES}

[1] Prasad, R., Kumar, V., and Prasad, S. K. (2014), Nanotechnology in Sustainable Agriculture: Present Concerns and Future Aspects, African Journal of Biotechnology, Vol. 13(6): 705-713.

[2] Bandyopadhyay, K. A. (2007), Nano Materials, New Age International Publishes, New Delhi.

[3] Rauwel, P., Rauwel, E., Ferdov, S and Singh, P. M. (2015), Silver nanoparticles: synthesis, properties and applications, Advances in Materials science and Engineering, 2015. 
[4] Tran, H. Q., Nguyen, Q. V. and Le, Anh-Tuan (2013), Silver nanoparticles: synthesis, properties, toxicology, applications and perspectives, Advances in Natural Sciences: Nanoscience and Nanotechnology, 4(3).

[5] Ennock, J and Ehrenpreis, D. (2018), Good Health: A Cornerstone of Development, OECD, Paris.

[6] Ahmed, S., Ahmad, M., Swami, L. B. and Ikram, S. (2016), A review on plant extract mediated synthesis of silver nanoparticles for antimicrobial applications: A green expertise, Journal of Advance Research, 7(1): $17-28$.

[7] Zhan, G., Huang, J., Lin, L., Lin, W., Emmanuel, K. and Li, Q. (2011), synthesis of gold nanoparticles by Cacumen platycladi leaf extract and its simulated solution toward the plant-mediated biosynthisis mechanism, J. Nanopart. Res. 13: 4957- 4968.

[8] Mody, V. V., Siwale, R., Singh, A. and Hardik, R. M. (2010), Introduction to metallic nanoparticles, J. Pharm Bioallied Sci. 2(4), $282-289$

[9] Zhang, H. (2013), Application of silver nanoparticles in drinking water purification, PhD. Thesis, University of Rhode Island, USA.

[10] Krutyakov, Y. A., Kudrynskiy, A. A., Olenin, A. Y. and Lisichkin, G. V. (2008) Russ. Chem. Rev. 77 (233).

[11] Ahamed, M. Alsalhi, M. S. and Siddiqui, M. K. (2010) Clin. Chim. Acta 411: 1841.

[12] García-Barrasa, J., López-de-luzuriaga, J. M. and Monge, M. (2011) Cent. Eur. J. Chem. 9(17).

[13] Kholoud, M. M., El-Nour, A., Eftaiha, A. and Al-Warthan, A. (2010), Synthesis and applications of silver nanoparticles, Arabian Journal of Chemistry, 3(3): $135-140$.

[14] Chung, III-Min, Park, I., Seung-Hyun, K., Thiruvengadam, M. and Rajakumar, G. I2016), Plantmediated synthesis of silver nanoparticles: Their characteristic properties and therapeutic applications, Nanoscale Research Letter, 11(40).

[15] Roy, S. and Das, K. T. (2015), Plant mediated green synthesis of silver nanoparticles - A review, International Journal of Plant Biology \& Research, 3(3): 1044.

[16] Song, Y. J. and Kim, S. B. (2008), Rapid biological synthesis of silver nanoparticles using plant leaf extracts, Bioprocess and Biosystems Engineering, 32(1): $79-84$.

[17] Pelczar, J. M., Chan, C. S. E. and Krieg, R. N. (1993), Microbiology - Concepts and Applications, Mc GrawHill, INC, New York.

[18] Gopinath, K., Gowri, S. and Arumugam, A. J. (2013), Phytosynthesis of silver nanoparticles using Pterocarpus santalinus leaf extract and their antibacterial properties Nanostruct Chem (2013) 3:68.

[19] Rather, Y. M., Pandian, J. K., Sundarapandian, M. S. and Yogamoorthi, A. (2017), Biosynthesis and characterization of silver nanoparticles using leaf extract of Wedelia urticifolia and evaluation of antibacterial efficacy, Journal of Pharmacy and Biological Sciences, 12(4): 14-23. 
David Timi, Subramaniyam Gopalakrishnan and Macquin Maino; Antimicrobial Application and Assessment of Green Synthesized Silver Nanoparticles Using Aqueous Leaf Extract of Ficus Copiosa. Journal of Biomedical Engineering and Medical Imaging, Volume 6, No 3, June (2019), pp 6-15

[20] Ponarulselvam, S., Panneerslvam, C., Murugan, K., Aarthi, N., Kalimuthu, K. and Thangamani, S. (2012), Synthesis of silver nanoparticles using leaves of Catharanthus roseus Linn. G. Don and their antiplasmodial activities, Asian Pacific Journal of Tropical Biomedicine, 2(7): $574-580$.

[21] Ficus copiosa (PROSEA) - PlantUse https://uses.plantnet-project.org/en/Ficus_copiosa_(PROSEA) Accessed 7/11/2018.

[22] Holdsworth, D. K. (1977), Medicinal Plants of PNG, Technical Paper No. 175, South Pacific Commission, Noumea, $1-3$.

[23] Waruruai, J., Sipana, B., Koch, M., Barrows R. L., Maitainaho, K. T. and Rai, P. P. (2011), An ethnobotanical survey of medicinal plants used in the Siwai and Buin districts of the Autonomous Region of Bougainville, J. Ethnopharmacol. 138(2): $564-577$.

[24] Wau, S. J. (2013), Phytochemical and Antimicrobial Assessment of Ficus botryocarpa (Moraceae), MPhil. Thesis, PNG University of Technology, Lae. PNG.

[25] Gopinath, K., Gowri, S. and Arumugam, A. J. (2013), Phytosynthesis of silver nanoparticles using Pterocarpus santalinus leaf extract and their antibacterial properties Nanostruct Chem (2013) 3:68.

[26] Roberts, M. R., Gilbert, C. J., Rodewald, B. L. and Wingrove, S. A. (1985), Modern Experimental Organic Chemistry, 4th ed., Saunders College Publishing, Philadelphia, USA.

[27] Andrews JM. Determination of minimum inhibitory concentration, Journal of Antimicrobial Chemotherapy, 2001, 48(1): 5- 16.

[28] Lok, CN., Ho, CM., Chen, R., He, QY,. Yu, WY., Sun, H., Tam, PKH., Chiu, JF. and Che, CM. (2007), Silver nanoparticles: partial oxidation and antibacterial activities, Journal of Biological Inorganic Chemistry, 12(4): $527-534$.

[29] Jyoti, K., Baunthiyal, M. and Singh, A. (2016), Characterization of silver nanoparticles synthesized using Urtica dioica Linn. leaves and their synergistic effects with antibiotics, Journal of Radiation Research and Applied Sciences, 9: 217-227. 